\title{
A Study on the Application of Automatic Scoring and Feedback System in College English Writing
}

\author{
https://doi.org/10.3991/ijet.v13i03.8386 \\ Xiaoxiao Lv \\ Shandong University of Science and Technology, Qingdao, China \\ $\operatorname{lvxx} 2007 @ 126 . \mathrm{com}$
}

\begin{abstract}
With the rapid development of computer technology and the need of college English teaching, the automatic grading of college students' English writing level is an inevitable trend. This is the inevitable result of the combination of computer technology and English teaching. The theoretical basis of this paper is the feedback of English writing and related theories introduced as follows. This paper analyzes the influence of automatic scoring and feedback system on English writing level via testing the variation of student composition's grammar, structure, length and grade in a teaching experiment. The experimental results indicate that online feedback is effective in evaluating students' English writing proficiency, which can help students improve their writing proficiency and independent writing ability. The students' attitudes and views towards automatic grading and feedback system were investigated with 118 students in the English experiment class of SUST as the test object. The research results can suggest a guide line in the improvement of college students' writing competence and evaluation of the effect of automatic scoring feedback system.
\end{abstract}

Keywords-College English writing, teaching experiment, English writing feedback, automatic scoring and feedback system

\section{Introduction}

Entering the era of "global village", people interact with each other in much larger space. English is the most widely learned and used foreign language across the globe [1]. As an important form of English language output, English writing is the focus in the Chinese academic world. Writing holds the key to the four language skills of "listening, speaking, reading and writing". Not only is it an important means to express emotions and consciousness, but it also embodies the comprehensive abilities to use language. Language use is reflected in vocabulary, grammar, sentence structure, text organization, and logical reasoning and argumentation [2]. English writing is of great importance in foreign language learning. Therefore, how to improve college English writing teaching becomes a popular research issue in college English writing studies [3]. 
With the rapid development and multiple applications of computer technology and multimedia Internet technology, college English writing is armed with modern information technology. When writing English compositions following the process of "thinking - writing - modifying - rethinking", students will receive great help from the automatic scoring and feedback mechanism in computer technology [4]. We will not deny the fact that the online automatic scoring and feedback system has not been popularized in domestic teaching practice, but it should embrace a good application prospect in English writing teaching considering its benefit to English writing [5].

The existing studies on the impact of the online automatic scoring and feedback system on college English writing levels are short of depth and case studies [6]. Therefore, in addition to the introduction of relevant fundamentals of English writing feedback, we also designed a teaching experiment to test the effect of the online automatic scoring and feedback system on college English writing. In doing so, the compositions of 118 students of 2015 in the English Experimental Class of SUST are instructed and assessed by using the scoring and feedback system. The teaching test lasts for a whole academic year and divided into three phases to generate statistical data of the compositions' score, length, grammar and text organization. After analyzing these data, we use a questionnaire to investigate the students' attitude towards and recognition degree of the system. Our research results are instructive in popularizing the online automatic scoring and feedback system among English writing teaching in China. What is more, with a case study, the system is verified positive in improving student's overall level of English writing.

\section{Theoretical basis}

\subsection{English writing feedback}

Feedback is the theoretical concept in automatic control, which occurs when outputs of a system are routed back as inputs that affect the output results [7]. This idea can be applied to English writing, in which the articles are firstly commented or modified by readers, and then returned to the writers who will revise the articles according to the comments and modifications. In this way, the articles will be less erroneous and of higher quality. The feedback information can be obtained from in-class interactions, or from teacher comments and classmate opinions. Feedback can draw writers' attention and provoke their thinking in the target language, helping in expressing themselves succinctly and accurately [8].

The two elements of feedback are evaluation and correction: evaluation is the readers' score of an article in terms of the integrity and generality; correction is the reader's detailed explanation and guidance on the articles.

In forms, English writing feedback can be divided into oral feedback and written feedback. In sources, feedback can be divided into teacher feedback, classmate feedback, and computer feedback. Computer feedback is the main source of feedback used in this article; computers or network systems are the provider and processor of feedbacks on student compositions. Teacher feedback is disadvantageous in stimulat- 
ing students' subjective initiatives of follow-up composition writing because of its subjective nature and students' strong dependence on it [9]. Although peer feedback allows students to further interact with each other while learning materials more effectively. However, due to the limited effect and application scope, it is necessary to combine peer feedback with other feedback sources. The computer English writing feedback has become the future development direction and trend of English feedback, and its combination with English writing teaching will exert a positive effect on college students' English writing and comprehensive English proficiency.

\subsection{Theories on English writing}

Theories on process writing. Process writing is to teach writing, focusing on the process of writing rather than the final result. Feedback learning is also an organic part of process writing theory, which can fully play its role if being implemented in each sub-process of writing [10].

Output hypothesis theory. When trying to express themselves in a language, language learners will realize that their language ability is not good enough to express exactly their points. This consciousness is evoked by internal and external feedbacks which can improve learners' self-reflection and initiative of language learning [11].

Interactive hypothesis theory. "Interaction" refers to the process of intercourse and interaction between people with language as the carrier. In acquiring second language, learners express themselves completely by "inputting - feeding back - correcting - reinputting". Feeding back is important in this theory, as learners can find some error through the feedbacks from teachers and correct them in time [12].

Through the above English writing theories, it is not difficult to highlight the importance of feedback learning in English writing. In our opinions, feedback learning should be expanded to all links in English writing. On the one hand, feedbacks can draw writers' attention and provoke their thinking in the target language; on the other hand, feedbacks can improve English writing levels and capacities.

\section{Introduction to the computer network automatic score feedback system}

In this paper, we use the sentence feedback system Pigal.org (Jukuu) as our feedback and scoring system, which is based on computer corpus and cloud computing. It is an online automatic scoring system, which is aimed to reduce the workload of teachers and provide a new mode of computer writing feedback to improve the English levels [13].

Students can do the homework in Jukuu and submit the finished version online. After receiving the composition, the system will immediately correct it, score it, and offer comments and recommendations both at the composition level and sentence by sentence [14]. Meanwhile, the system provides student users with expanded learning of knowledge, recommended lexical colocations, reference sentences, etc.; students 
can correct their articles by using the feedback functions of Jukuu [15]. Figure 1 is the screenshot of Jukuu feedbacks on student compositions

Technological innovation and human life 查着要求

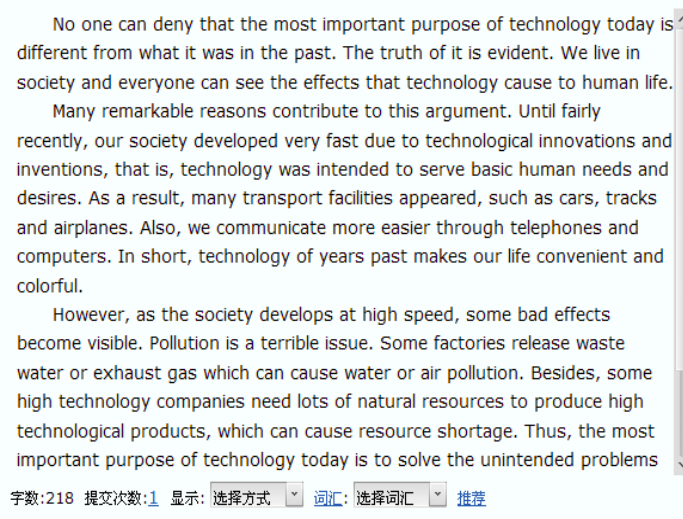

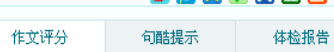

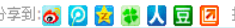

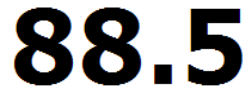

\section{间汇:}

句子:

篇章结构:

内容相关:

排名:共108篇，本文排名 $18 ，$ 最高分 91.5 , 最低分70

司类丰富，未发现拼写错误，同时过灌词和衔接词 也很丰富

选择常用评语

Fig. 1. The Screenshot of Jukuu

\section{An empirical study on the influence of computer network automatic scoring system on english writing}

\subsection{Research objects}

Our research objects are 59 students of 2015 in English Experimental Class 1 and another 59 students of 2015 in English Experimental Class 2 in SUST. All the students come from different institutes with different majors. Their English levels are equivalent to each other according to the results of an English test took before they come to the campus.

\subsection{Research methods and statistical tools}

\section{Research methods.}

1. Comparative analysis. Our experiment lasted for a whole academic year from September 2015 to July 2016. The sampling time was in November 2015 (the first time), March 2016 (the second time), and May 2016 (the third time), respectively. The sampling data were used to compare the changes in composition scores, length, grammar, and text structure [16].

2. Questionnaire survey. This method was to collect the statistics of how Jukuu impressed students and students' attitudes towards Jukuu.

Statistical tools. For statistical data and questionnaire survey, we used Word, Excel and other software analysis system to deal with data. 


\subsection{Research data analysis}

In the academic year, the randomized 46 compositions in three topics were selected as the samples. The composition titles are listed in Table 1.

Overall score comparison analysis. After students submit a composition, the automatic scoring and feedback system will generate some points out of 100 . The scores in three sampling time is shown in Table 2, and the variation trend of general scores is shown in Figure 2.

Table 1. Writing samples

\begin{tabular}{|c|c|l|l|}
\hline Stage & Date & \multicolumn{1}{|c|}{ Article title } & \multicolumn{1}{c|}{ Requirement } \\
\hline The first & 2015.11 & $\begin{array}{l}\text { Technological } \\
\text { innovation and } \\
\text { human life }\end{array}$ & $\begin{array}{l}\text { You should use the precise language to develop your ideas } \\
\text { clearly. Each paragraph must contain a clear argument and } \\
\text { enough and appropriate supporting evidences or examples } \\
(100-500 w o r d s)\end{array}$ \\
The second & 2016.03 & $\begin{array}{l}\text { Language and } \\
\text { If people write in English, their work will have the chance } \\
\text { of reaching a worldwide audience; but to write in English } \\
\text { may mean sacrificing their cultural identity. (100-500words })\end{array}$ \\
\hline The third & 2016.05 & $\begin{array}{l}\text { Are women stronger } \\
\text { than men }\end{array}$ & $\begin{array}{l}\text { In what way can you say women are stronger than men } \\
(100-500 \text { words })\end{array}$ \\
\hline
\end{tabular}

Table 2. The statistical results of general scores

\begin{tabular}{lcccc}
\hline \multicolumn{1}{c}{ Stage $\backslash$ Score } & $\mathbf{6 0 - 6 9 . 5}$ & $\mathbf{7 0 - 7 9 . 5}$ & $\mathbf{8 0 - 8 9 . 5}$ & $\mathbf{9 0 - 1 0 0}$ \\
\hline The first & $2(4.3 \%)$ & $14(30.4 \%)$ & $25(54.3 \%)$ & $5(10.9 \%)$ \\
The second & 0 & $18(39.1 \%)$ & $20(43.5 \%)$ & $8(17.4 \%)$ \\
The third & 0 & $10(21.7 \%)$ & $18(39.1 \%)$ & $18(39.1 \%)$ \\
\hline
\end{tabular}

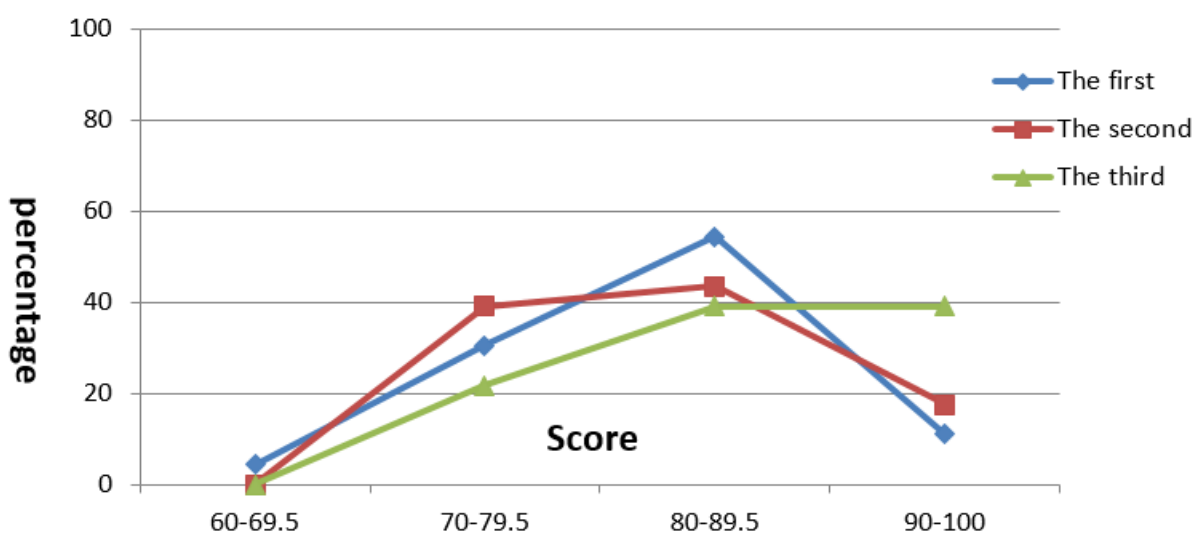

Fig. 2. The variation trend of general scores

The composition scores were divided into four grades: 60-69.5, 70-79.5, 80-89.5, 90-100. As shown in the table 2, for the first sampling time, there were respective 2, 14,25 and 5 pieces of articles in the four grades; for the second sampling time, there 
were respective $0,18,20$ and 8 pieces of articles in the four grades; for the third sampling time, there were respective $0,10,18$ and 18 pieces of articles in the four grades. The less low-score compositions and more high-score compositions shows an upward trend of general scores due to the accumulated English practice in the system over time. Figure 2 indicates that the proportion of excellent compositions (scored between 90 and 100 ) increases from the initial $10.9 \%$ to $17.4 \%$, finally hitting $39.1 \%$.

Comparison of composition length. English writing has specific requirements for length, so the automatic score feedback system will include composition length in evaluation. As shown in Table 3, the passing rate of composition length exceeds $95 \%$ in the three sampling time, and the number of compositions that meet the requirement of length varies little in different sampling time. Therefore, system feedback has little effect on composition length, as students have already reminded themselves to write enough words.

Analysis of grammatical errors. This article mainly classifies the grammatical errors in Chinglish, vocabulary, grammar and technical details. The statistical results are shown in Fig. 3 and Table 4.

Chinglish refers to ungrammatical or nonsensical written English language that is influenced by both the ways of thinking and expression of Chinese language and the Chinese culture that is different from English culture. Chinese college students always use Chinglish in English writing. Figure 3 and Table 4 show that Chinglish occurs much more frequently than other errors. Chinglish mainly occurs in the forms of collocation mistakes, wrong sentence cohesion, and different choices of words. For example, in expressing the causal relationship, students always mix and match "because" and "so".

Table 3. The statistical results of quantity of composition words

\begin{tabular}{lcc}
\hline & Standard composition number & Standardized rate \\
\hline The first & 46 & $100 \%$ \\
The second & 44 & $95.7 \%$ \\
The third & 44 & $95.7 \%$ \\
\hline
\end{tabular}

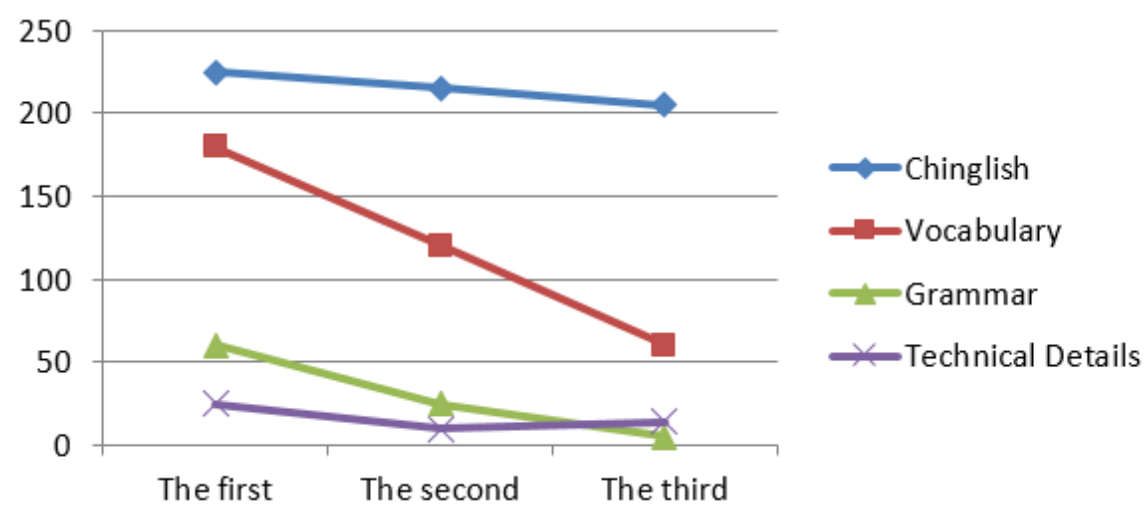

Fig. 3. The diagram of language errors 
Table 4. The statistical results of language errors variation

\begin{tabular}{|l|c|c|c|}
\hline \multicolumn{1}{|c|}{ Type of error|Trend } & Decrease & Un-change & Increase \\
\hline Chinglish & $29(63 \%)$ & $6(13 \%)$ & $11(24 \%)$ \\
\hline Vocabulary & $31(67.4 \%)$ & $6(13 \%)$ & $9(19.6 \%)$ \\
\hline Grammar & $27(58.7 \%)$ & $15(32.6 \%)$ & $4(8.7 \%)$ \\
\hline Technical detail & $12(26.1 \%)$ & $28(58.7 \%)$ & $7(15.2 \%)$ \\
\hline
\end{tabular}

How students master vocabularies can be evaluated by the frequency of advanced vocabulary in English compositions. In other words, the more frequent low-level vocabularies are, the more basic the writing level is. We use Jukuu to collect 374 high-frequency low-level words, 189 of which used in the first sampling time, 123 of which used in the second sampling time, and 22 of which used in the third sampling time. The change of frequency of use indicates that under the guidance of the scoring and feedback system, students consciously improve the level of English writing by reducing the use of low-level words.

One of the major types of error in students' English is grammatical error, for which the system provides corresponding advice of rectification. The statistical result shows that the amount of grammatical error is reduced from 61 to 24 and finally to 9 , and that the average amount of grammatical error per article records a significantly downward trend. This phenomenon shows that system feedback can help students reduce grammatical errors.

In terms of technical details, errors differ little before and after system feedback for $58.7 \%$ of students, while $26.1 \%$ students make much less technical mistakes under the guidance of system feedback. This result verifies the effectiveness of the scoring and feedback system in reducing technical errors.

Comparison of text structure. Text structure is mainly reflected in the number of sentences and paragraphs. A composition must have 11-17 sentences distributed in 35 paragraphs, as required by the system. According to our statistic results, in all the sampling time, over $80 \%$ of compositions have 3-5 paragraphs and $40 \%-50 \%$ of compositions have 11-17 sentences, which meets the system requirements. Therefore, the system scores and feedback have little effect on the text structure.

\subsection{Student attitude survey statistics}

Students' comments on the feedback are shown in table 5.

A questionnaire survey is conducted on the 118 students participating in the teaching experiment, which investigates students' impression on the system, the system application, and how the system helps students improve their English level. The survey results show that the automatic scoring and feedback system impresses students greatly, with $85 \%$ students thinking highly of the system. More than $80 \%$ participants think that the system is helpful in improving their English levels. 
Table 5. The student's attitude toward Juku's feedback

\begin{tabular}{|l|c|c|c|}
\hline \multicolumn{1}{|c|}{ Survey points } & $\begin{array}{c}\text { Very helpful } \\
\text { (Attitude) }\end{array}$ & $\begin{array}{c}\text { Normal } \\
\text { (Attitude) }\end{array}$ & $\begin{array}{c}\text { Helpless } \\
\text { (Attitude) }\end{array}$ \\
\hline The overall impression & 100 & 15 & 3 \\
The usage of automatic scoring system & 90 & 20 & 8 \\
\hline Impact on the level of English Writing & 95 & 10 & 13 \\
\hline
\end{tabular}

\section{Conclusion}

Based on the theoretical knowledge, this paper validates the positive effect of the online scoring and feedback system on college students' English writing level by designing teaching examples and a questionnaire survey. We draw the following instructive conclusions:

1. The online scoring and feedback system can improve the overall score of college students' composition and effectively reduce grammatical errors; but it has little effect on composition length and text structure.

2. College English writing is generally problematic in Chinglish and sentence structure, which should be trained intensely.

3. In general, the online scoring and feedback system has a positive effect on the improvement of college students' English writing level. Its popularization and application can reduce the workload of teachers and enhance the students' initiatives and English writing level.

\section{References}

[1] Manning, A. (2008). English for language and linguistics in higher education studies, Journal of Structural Biology, 162(3), 397-403.

[2] Chen, J., Hsu, A.Y. (2010). Beyond the writing process: the role of writing strategy, writing task, and writing proficiency. Journal of the American Chemical Society, 124(7), 1276-1287.

[3] Reiss, T.J. (2005). Andrew Barnaby; Lisa J. Schnell: literate experience: the work of knowing in seventeenth century English writing. Isis, 96(3), pp. 430-431. https://doi.org/10.1086/498770

[4] Zheng, W. (2016). A study on the integration of computer network technology and College English Curriculum. The Workshop on Advanced Research \& Technology in Industry Applications. https://doi.org/10.2991/wartia-16.2016.3

[5] Guo, Z., Xu, L. (2016). Study on the integration mode of computer network technology and college English curriculum. International Journal of Emerging Technologies in Learning, 11(8), 40. https://doi.org/10.3991/ijet.v11i08.6046

[6] Srihari, S., Collins, J., Srihari, R., Srinivasan, H., Shetty, S., Brutt-Griffler, J. (2008). Automatic scoring of short handwritten essays in reading comprehension tests. Artificial Intelligence, 172(2), 300-324. https://doi.org/10.1016/j.artint.2007.06.005

[7] Cardella, M.E., Diefes-Dux, H.A., Marbouti, F. (2015). Written feedback on design: a comparison of students and educators. International Journal of Engineering Education. 
[8] Wang, F., Wang, S. (2012). A comparative study on the influence of automated evaluation system and teacher grading on students' English writing. Procedia Engineering, 29, 993997. https://doi.org/10.1016/j.proeng.2012.01.077

[9] Liu, M., Li, Y., Xu, W., Liu, L. (1939). Automated essay feedback generation and its impact in the revision. IEEE Transactions on Learning Technologies, pp. 99https://doi.org/10.1109/TLT.2016.2612659

[10] Masse, R.E. (2013). Theory and practice of writing processes for technical writers. IEEE Transactions on Professional Communication, 27(4), 185-192. https://doi.org/10.1109/ TPC.1984.6448733

[11] Schwind, C., Siegel, P. (1994). A modal logic for hypothesis theory. Fundamenta Informaticae, 21(1), 89-102.

[12] Freeman, J.B., Ambady, N. (2011). A dynamic interactive theory of person construal. Psychological Review, 118(2), 247-79. https://doi.org/10.1037/a0022327

[13] Alghamdi, M., Alkanhal, M., Al-Badrashiny, M., Al-Qabbany, A., Areshey, A., Alharbi, A. (2014). A hybrid automatic scoring system for Arabic essays. Ai Communications, 27(2), 103-111. https://doi.org/10.3233/AIC-130586

[14] Li, J., Pan, W., Zhang, R., Chen, F., Nie, S., He, X. (2010). Design and implementation of semantic matching based automatic scoring system for $\mathrm{C}$ programming language. Lecture Notes in Computer Science, 6249, 247-257. https://doi.org/10.1007/978-3-642-14533$\underline{925}$

[15] Yong, S.C., Kong, J.L. (2015). Context-sensitive word error detection and correction for automatic scoring system of English writing. KTSDE, 4(1), 45-56. https://doi.org/10.3745/ KTSDE.2015.4.1.45

[16] Li, Y.L. (2013). Review on the application of automatic scoring system: enlightenment to college English writing teaching. Educational Research on Foreign Languages \& Arts.

\section{Author}

Xiaoxiao Lv is an English teacher at the College of Foreign Languages, Shandong University of Science and Technology, Qingdao 266590, China whose research interests lie in TESOL and English literature.

Article submitted 07 February 2018. Final acceptance 23 February 2018. Final version published as submitted by the author. 